\title{
Transmissão e Patogenicidade de Phomopsis sp. Associadas às Sementes de Angico-vermelho (Parapiptadenia rigida Benth.)
}

\author{
Clair Walker ${ }^{1}$, Caciara Gonzatto Maciel², Marciéli Pitorini Bovolini², \\ Camila Schultz Pollet ${ }^{2}$, Marlove Fátima Brião Muniz ${ }^{2}$
}

${ }^{1}$ Departamento de Defesa Fitossanitária, Universidade Federal de Santa Maria - UFSM, Santa Maria/RS, Brasil ${ }^{2}$ Defesa Fitossanitária, Universidade Federal de Santa Maria - UFSM, Santa Maria/RS, Brasil

\section{RESUMO}

O estudo da associação de fungos com sementes pode gerar informações importantes, pois alguns desses microrganismos podem causar danos às sementes, além de afetar a produção de mudas. Este trabalho teve como objetivos avaliar a germinação e fazer um levantamento dos fungos associados às sementes de três lotes de angico-vermelho (Parapiptadenia rigida) procedentes de São João do Oeste-SC (SJO), Sobradinho-RS (SO) e Santa Cruz do Sul-RS (SCS), além de detectar a transmissão e a patogenicidade dos fungos associados às sementes. Por meio do teste de sanidade, foi detectada a presença do gênero Phomopsis sp. como potencialmente patogênico e dois gêneros fúngicos de armazenamento, Penicillium sp. e Aspergillus sp. Dentre as procedências testadas (SJO e SCS), foi verificada a transmissão e a patogenicidade de Phomopsis sp. para a procedência SCS, que provocou lesões necróticas escuras nos bordos dos folíolos, enrugamento das sementes não germinadas e redução da porcentagem de emergência das plântulas em viveiro.

Palavras-chave: patologia de sementes, germinação, sementes florestais.

\section{Transmission and Pathogenicity of Phomopsis sp. Associated with Seeds of Angico-vermelho (Parapiptadenia rigida Benth.)}

\begin{abstract}
The study of seed-borne fungi in forest seeds may bring important information because some of these microorganisms can cause damage to seeds as well as to the production of seedlings. This research aimed to evaluate germination and survey the seed-borne fungi of three lots of angicovermelho (Parapiptadenia) from São João do Oeste, Santa Catarina state (SJO), Sobradinho (SO) and Santa Cruz do Sul, Rio Grande do Sul state (SCS), in addition to detecting their transmission and pathogenicity. The presence of the fungal genus Phomopsis sp as potentially pathogenic and the saprophytic fungi Penicillium sp. and Aspergillus sp. was detected through seed health testing. Among the lots tested (SJO and SCS), transmission and pathogenicity of Phomopsis sp was verified in the SCS lot, causing dark necrotic lesions on the folioles edges, wrinkling of ungerminated seeds, and percentage reduction of seedling emergence in seedplots.
\end{abstract}

Keywords: seed pathology, germination, forest seeds. 


\section{INTRODUÇÃO}

O angico-vermelho (Parapiptadenia rigida Benth.), pertencente à família Fabaceae, é uma espécie arbórea, de ocorrência natural no Brasil (Carvalho, 2003), mais frequente nos três Estados sulinos, na mata latifoliada semidecídua da Bacia do Paraná (Lorenzi, 2008). Produz madeira de excelente qualidade, com densidade de 0,85 g $\mathrm{cm}^{-3}$, bastante dura, muito resistente e de grande durabilidade sob condições naturais. Por essas características, é utilizada em obras hidráulicas e expostas, como postes, estacas e dormentes. A casca é rica em tanino e suas flores são melíferas. Além das utilidades mencionadas, o angico-vermelho possui características ornamentais que a recomendam para o paisagismo em geral (Lorenzi, 2008).

A produção de mudas de qualidade requer a utilização de sementes e material propagativo sadio. De acordo com Resende et al. (2008), aproximadamente $90 \%$ das doenças que ocorrem em viveiros florestais são causadas por fungos, sendo que uma das fontes de contaminação para o aparecimento desses fungos é a semente utilizada. $\mathrm{O}$ aparecimento desses organismos pode causar tombamento de mudas, podridões de raízes e diversas manchas foliares. Santos et al. (2001) alertam para uma maior atenção com os fungos associados às sementes de espécies nativas, pois alguns destes microrganismos podem causar danos à qualidade e à produção de mudas.

Contribuições importantes para identificação de fungos presentes em sementes de espécies florestais têm sido obtidas em diversos trabalhos, nos quais os autores constataram a incidência de fungos, como Cladosporium cladosporioides, Pestalotiopsis maculans, Fusarium sp., Epicoccum sp., Alternaria sp., Colletotrichum sp., Curvularia sp., Pestalotia sp., Phoma sp., Phomopsis sp. e Aspergillus sp. (Padulla et al., 2010; Lazarotto et al., 2010; Botelho et al., 2008). No entanto, ainda faltam informações em relação aos efeitos que esses fungos causam na germinação das sementes e no desenvolvimento das plântulas. Para Mendes et al. (2005), a obtenção de uma muda de qualidade está diretamente relacionada ao controle sanitário da semente utilizada, uma vez que esta poderá servir como fonte de inóculo e veículo de disseminação e propagação de patógenos. Devido à escassez de informações em relação aos patógenos que causam danos às sementes de angico-vermelho, o presente trabalho tem como objetivos avaliar a germinação e a sanidade de lotes de sementes, além de detectar a transmissão e patogenicidade dos fungos associados às sementes.

\section{MATERIAL E MÉTODOS}

As sementes de angico-vermelho foram provenientes de três locais: a amostra SJO foi coletada e beneficiada em São João do OesteSC, no mês de julho de 2011. Posteriormente, as sementes foram armazenadas por uma semana em embalagens plásticas, em geladeira com temperatura de $10 \pm 2{ }^{\circ} \mathrm{C}$ até a realização do experimento. As sementes das amostras SCS (Santa Cruz do SulRS) e SO (Sobradinho-RS) foram obtidas por meio do programa Bolsa de Sementes, pertencente ao Convênio entre a Universidade Federal de Santa Maria (UFSM) e a Associação dos Fumicultores do Brasil (AFUBRA), sendo coletadas e beneficiadas em junho de 2011, por alunos do Ensino Fundamental de escolas públicas do Rio Grande do Sul participantes do programa. $\mathrm{O}$ armazenamento das mesmas foi realizado no Viveiro Florestal da UFSM em embalagens de papel e plástico, em câmara fria úmida, com aproximadamente $70 \%$ de umidade e temperatura de $10 \pm 2{ }^{\circ} \mathrm{C}$.

Os lotes de sementes foram conduzidos ao Laboratório de Fitopatologia do Departamento de Defesa Fitossanitária do Centro de Ciências Rurais, na Universidade Federal de Santa Maria (UFSM), e o teste de patogenicidade foi realizado no Viveiro Florestal da UFSM. As sementes foram submetidas às seguintes avaliações:

Germinação: conduzida em rolo de papel germitest, em câmara com temperatura controlada a $25 \pm 2{ }^{\circ} \mathrm{C}$ e fotoperíodo de 12 horas de luz ultravioleta e 12 horas no escuro. As sementes foram distribuídas sobre duas folhas de papel (previamente umedecidas com água destilada e esterilizada). $\mathrm{Na}$ primeira contagem, avaliou-se apenas a porcentagem de plântulas normais, sendo esta realizada aos sete dias após a instalação do experimento. Foram 
consideradas como germinadas, as sementes que emitiram radícula e expuseram os cotilédones. A segunda contagem foi realizada aos 14 dias, quando foi avaliada a porcentagem de plântulas normais, plântulas anormais, sementes duras e mortas. Foram consideradas como plântulas normais aquelas que apresentaram as estruturas essenciais do embrião desenvolvidas, segundo definição das Regras para Análise de Sementes (Brasil, 2009). Além disso, foi medido o comprimento de plântulas $(\mathrm{cm})$, com auxílio de régua graduada.

Sanidade: utilizou-se o método do papel filtro (Blotter test), segundo as RAS (Brasil, 2009). As sementes foram distribuídas em caixas de plástico transparente (gerbox) previamente desinfetadas com solução de hipoclorito de sódio $1 \%$ e álcool $70 \%$, forradas com duas folhas de papel-filtro esterilizadas e umedecidas com água destilada esterilizada. Utilizaram-se 100 sementes não desinfetadas, divididas em quatro repetições de 25 sementes. A incubação foi realizada em câmara com temperatura controlada a $25 \pm 2{ }^{\circ} \mathrm{C}$ e fotoperíodo de 12 horas de luz ultravioleta e 12 horas no escuro, durante sete dias. A verificação da ocorrência de fungos foi feita com auxílio de microscópio estereoscópico, sendo as sementes observadas individualmente. Quando encontrada alguma estrutura fúngica, esta era então transferida para lâminas com corante (lactofenol com azul de metileno) e analisada com auxílio do microscópio óptico. A identificação dos fungos foi realizada conforme descrições de Barnett \& Hunter (1972).

Avaliação da transmissão e da patogenicidade: $\mathrm{O}$ teste de patogenicidade foi realizado nas amostras SJO e SCS, que apresentaram maior incidência de Phomopsis sp. O fungo, isolado das sementes de angico-vermelho, foi transferido para placas de Petri, esterilizadas, contendo meio de cultura BDA (batatadextrose-ágar), para produção do inóculo. As placas foram mantidas em câmara de incubação do tipo BOD à temperatura de $25 \pm 2{ }^{\circ} \mathrm{C}$ e fotoperíodo de 12 horas por sete dias.

Após o período de incubação, foi realizada a inoculação do fungo nas sementes por meio do método de contato com a cultura fúngica. Para tal, as sementes foram previamente desinfestadas com hipoclorito de sódio $1 \%$ e álcool $70 \%$ durante
30 segundos, enxaguadas em água destilada esterilizada e deixadas a secar sobre papel toalha. Posteriormente, as mesmas foram colocadas em contato com o fungo em placas de Petri e novamente incubadas por 72 horas nas mesmas condições descritas acima. Para a testemunha, a semeadura foi realizada em placas contendo apenas BDA.

Decorrido o período de incubação, as sementes foram semeadas em bandejas de isopor, utilizando-se uma semente por célula, contendo vermiculita como substrato. As bandejas permaneceram em condições de casa de vegetação com irrigação realizada por barra móvel de microaspersores com lâmina d'água de $5 \mathrm{~mm}$, controlada conforme a necessidade diária.

As avaliações foram realizadas aos sete, 14 e 21 dias após a semeadura, sendo consideradas como germinadas as sementes que expuseram os cotilédones. Aos 21 dias, procedeu-se à avaliação final de emergência, em que foram contabilizadas as plântulas normais, anormais e sementes não germinadas. As plântulas que apresentaram sintomas e as sementes não germinadas foram colocadas em câmara úmida com temperatura controlada a $25 \pm 2{ }^{\circ} \mathrm{C}$ e fotoperíodo de 12 horas de luz ultravioleta por sete dias, para o reisolamento do fungo.

Análise dos dados: Nos testes de germinação e sanidade, utilizou-se o delineamento estatístico inteiramente casualizado, com quatro repetições de 25 sementes; para o teste de patogenicidade, utilizouse arranjo bifatorial $2 \times 2$. O fator "A" referiu-se às procedências (SCS e SJO) e o fator "B" aos tratamentos (sementes inoculadas e não inoculadas com o fungo Phomopsis sp.). Os dados obtidos foram submetidos à análise da variância (Teste F). As médias entre os tratamentos foram comparadas pelo teste de Tukey $(\mathrm{P} \leq 0,05)$, usando-se o programa estatístico SISVAR (Ferreira, 2009).

\section{RESULTADOS E DISCUSSÃO}

Germinação: Em relação à porcentagem de plântulas normais germinadas $(G)$, as procedências SJO e SCS apresentaram as melhores médias, 97 e 80\%, respectivamente, não diferindo entre si (Tabela 1). Maciel et al. (2012) encontraram resultados semelhantes (88 e 91\% de germinação) para dois lotes da mesma espécie (Parapiptadenia 
rigida), provenientes do Rio Grande do Sul, utilizando-se o substrato folha de papel mataborrão. Mondo et al. (2008) encontraram 71\% de germinação em sementes de angico-vermelho ( $P$. rigida) coletadas em São Paulo, utilizando-se rolo de papel como substrato, na mesma temperatura de germinação utilizada neste trabalho $\left(25^{\circ} \mathrm{C}\right)$. Porém, o período de armazenamento das sementes foi de um ano e oito meses, superior às amostras de sementes deste trabalho.

Em relação à porcentagem de plântulas anormais, a procedência SO apresentou valores médios de 17\% para essa variável, diferindo da procedência SJO, que não teve nenhuma plântula anormal; porém, SO não apresentou diferença em relação à SCS (6\%) (Tabela 1).

A procedência SJO, além de apresentar a maior média de plântulas normais e nenhuma plântula anormal, obteve o maior comprimento de plântulas, diferindo das demais procedências (Tabela 1). Segundo Nakagawa (1999), o comprimento de plântulas é um parâmetro indicado para mensurar diferenças de vigor em plântulas, podendo-se considerar que amostras com maiores valores médios são as mais vigorosas. Com base nesses critérios avaliados, é possível constatar que as sementes procedentes de Sobradinho e Santa Cruz do Sul apresentaram qualidade inferior em relação à procedência São João do Oeste.

Sanidade das sementes em papel filtro: $\mathrm{Na}$ análise sanitária das sementes de angicovermelho foi encontrado apenas um gênero fúngico potencialmente patogênico - Phomopsis sp. - e dois gêneros fúngicos de armazenamento - Penicillium sp. e Aspergillus sp. (Tabela 2).

Phomopsis sp. teve $100 \%$ de incidência na procedência SJO, diferindo das demais procedências. No entanto, a alta incidência desse fungo nessa procedência não prejudicou a germinação, conforme foi observado na Tabela 1. Esse fato pode ser explicado pelo tempo reduzido entre a coleta e a realização do experimento, impossibilitando a ação do fungo sobre as sementes. De acordo com Carneiro (1987), Phomopsis sp. está relacionado a redução no potencial germinativo e podridão de sementes em espécies florestais. Nas procedências SCS e SO, a incidência de Phomopsis sp. foi de 31 e 7\%, respectivamente (Tabela 2). Resultados semelhantes foram apresentados por Strapasson et al. (2002), que detectaram a incidência de Phomopsis sp. em

Tabela 1. Teste de germinação em rolo de papel para as sementes de Parapiptadenia rigida das procedências de Santa Cruz do Sul (SCS), Sobradinho (SO) e São João do Oeste (SJO).

Table 1. Germination test in paper roll for the Parapitadenia rigida seeds from Santa Cruz do Sul (SCS), Sobradinho (SO) and São João do Oeste (SJO).

\begin{tabular}{ccccccc} 
Procedências & PCG $(\%)$ & G $(\%)$ & PA (\%) & SD (\%) & SM (\%) & CP (cm) \\
SCS & $47^{\mathrm{a}}$ & $91^{\mathrm{ab}}$ & $6^{\mathrm{ab}}$ & $0^{\mathrm{a}}$ & $1^{\mathrm{a}}$ & $10,25^{\mathrm{b}}$ \\
SO & $79^{\mathrm{a}}$ & $80^{\mathrm{b}}$ & $17^{\mathrm{a}}$ & $0^{\mathrm{a}}$ & $3^{\mathrm{a}}$ & $7,05^{\mathrm{b}}$ \\
SJO & $45^{\mathrm{a}}$ & $97^{\mathrm{a}}$ & $0^{\mathrm{b}}$ & $1^{\mathrm{a}}$ & $2^{\mathrm{a}}$ & $10,72^{\mathrm{a}}$ \\
\hline
\end{tabular}

${ }^{*}$ Médias seguidas por mesma letra, na coluna, não diferem entre si pelo teste de Tukey no nível de 5\% de probabilidade. PCG: Primeira Contagem de Germinação; G: Plântulas normais germinadas; PA: Plântulas Anormais; SD: Sementes Duras; SM: Sementes Mortas; CP: Comprimento de Plântulas.

Tabela 2. Incidência de fungos (\%), detectados pelo método papel filtro, associados às sementes de Parapiptadenia rigida coletadas em Santa Cruz do Sul (SCS), Sobradinho (SO) e São João do Oeste (SJO)

Table 2. Fungi incidence (\%) detected by the filter paper method, associated in the Parapiptadenia rigida seeds collected in Santa Cruz do Sul (SCS), Sobradinho (SO) and São João do Oeste (SJO).

\begin{tabular}{cccc} 
Procedências & \multicolumn{3}{c}{ Incidência Fúngica (\%) } \\
\cline { 2 - 4 } & Phomopsis sp. & Penicillium sp. & Aspergillus sp. \\
SCS & $31^{\mathrm{b} *}$ & $65^{\mathrm{a}}$ & $0^{\mathrm{a}}$ \\
SO & $7^{\mathrm{b}}$ & $30^{\mathrm{b}}$ & $1^{\mathrm{a}}$ \\
SJO & $100^{\mathrm{a}}$ & $0^{\mathrm{b}}$ & $0^{\mathrm{a}}$ \\
\hline
\end{tabular}

*Médias seguidas por mesma letra, na coluna, não diferem entre si pelo teste de Tukey no nível de $5 \%$ de probabilidade. 
sementes de outra espécie de angico (Piptadenia paniculata).

Em relação à ocorrência de Penicillium sp., a procedência SCS teve $65 \%$ de incidência, diferindo das demais, uma vez que SO e SJO apresentaram 30 e $0 \%$ de ocorrência, respectivamente. O fungo Aspergillus sp. esteve presente em apenas $1 \%$ das sementes na procedência $\mathrm{SO}$. O fato de não serem verificados os fungos Aspergillus sp. e Penicillium sp. na procedência SJO pode estar associado ao menor tempo em que essas sementes permaneceram armazenadas. Segundo Cherobini et al. (2008), esses fungos têm sua incidência aumentada em condições de armazenamento. Machado (1988) afirma que os gêneros Penicillium e Aspergillus, durante o período de armazenamento, podem ser altamente prejudiciais às sementes, causando a perda do poder germinativo, a descoloração e o apodrecimento. Além destes prejuízos, podem causar o aumento da taxa de ácidos graxos, provocando a rancificação de óleos e o aquecimento da massa da semente, com o consequente aumento da taxa de respiração.

Avaliação da transmissão e da patogenicidade: $\mathrm{Na}$ Tabela 3 são apresentados os resultados da influência de Phomospis sp. na emergência de plântulas em viveiro. Para a variável PCE, não ocorreu interação entre os fatores procedência e tratamentos (sementes inoculadas e não inoculadas).

Em relação à primeira contagem de emergência (7 dias), não foi verificada interação entre os fatores; por outro lado, observou-se diferença entre as procedências para essa variável. Verificou-se que as sementes de angico-vermelho inoculadas com Phomopsis sp. da procedência SCS tiveram o vigor prejudicado, apresentando $58 \%$ de plântulas normais na primeira contagem de emergência (PCE), diferindo da procedência SJO (84\%). Na segunda contagem de emergência (14 dias), uma tendência igual foi verificada, em que a procedência SCS apresentou a menor média de plântulas normais emergidas.

Para a variável emergência (21 dias), constatouse interação entre os fatores. Verificou-se diferença entre as sementes inoculadas e não inoculadas da amostra SCS, em que o percentual variou de $56 \%$ a $84 \%$, para sementes com e sem Phomopsis sp., respectivamente (Tabela 3). Por meio desse resultado, pode-se inferir que o fungo teve influência

Tabela 3. Emergência (\%) em viveiro de sementes de Parapiptadenia rigida inoculadas e não inoculadas com Phomopsis sp., para as procedências de Santa Cruz do Sul (SCS) e São João do Oeste (SJO).

Table 3. Emergence (\%) in nursery seeds Parapiptadenia rigida inoculated and not inoculated with Phomopsis sp., collected in Santa Cruz do Sul (SCS) and São João do Oeste (SJO).

\begin{tabular}{|c|c|c|c|c|}
\hline \multirow{2}{*}{ Variável } & \multirow{2}{*}{ Procedência } & \multicolumn{2}{|c|}{ Tratamentos } & \multirow{2}{*}{ Média (\%) } \\
\hline & & Sementes inoculadas & Sementes não inoculadas & \\
\hline PCE (7 dias) & SCS & $58,0^{\mathrm{Ab} *}$ & $74,0^{\mathrm{Aa}}$ & 66,0 \\
\hline CV(\%): 11,45 & SJO & $84,0^{\mathrm{Aa}}$ & $86,0^{\mathrm{Aa}}$ & 85,0 \\
\hline Média & & 71,0 & 80,0 & 75,5 \\
\hline E (14 dias) & SCS & $68,0^{\mathrm{Ab}}$ & $85,0^{\text {Aa }}$ & 76,5 \\
\hline $\mathrm{CV}(\%): 8,27$ & SJO & $90,0^{\mathrm{Aa}}$ & $88,0^{\mathrm{Aa}}$ & 89,0 \\
\hline Média & & 79,0 & 86,5 & 82,75 \\
\hline $\mathrm{E}$ (21 dias) & SCS & $56,0^{\mathrm{Bb}}$ & $84,0^{\mathrm{Aa}}$ & 70,0 \\
\hline $\mathrm{CV}(\%): 7,92$ & SJO & $86,0^{\mathrm{Aa}}$ & $83,0^{\mathrm{Aa}}$ & 84,5 \\
\hline Média & & 71,0 & 83,5 & 77,25 \\
\hline $\mathrm{PA}$ & SCS & $7,0^{\mathrm{Aa}}$ & $2,0^{\mathrm{Aa}}$ & 4,5 \\
\hline CV(\%): 28,92 & SJO & $4,0^{\mathrm{Aa}}$ & $10,0^{\mathrm{Bb}}$ & 7,0 \\
\hline Média & & 5,5 & 6,0 & 5,75 \\
\hline SNG & SCS & $37,0^{\mathrm{Bb}}$ & $14,0^{\mathrm{Aa}}$ & 25,5 \\
\hline CV(\%): 30,97 & SJO & $10,0^{\mathrm{Aa}}$ & $7,0^{\mathrm{Aa}}$ & 8,5 \\
\hline Média & & 23,5 & 10,5 & 17,0 \\
\hline
\end{tabular}

${ }^{*}$ Médias seguidas de letras diferentes, minúsculas na coluna e maiúsculas na linha, diferem entre si pelo teste de Tukey no nível de 5\% de probabilidade. PCE: Primeira Contagem de Emergência; E: Plântulas normais Emergidas; PA: Plântulas Anormais; SNG: Sementes Não Germinadas. $\mathrm{CV}(\%)=$ coeficiente de variação. 

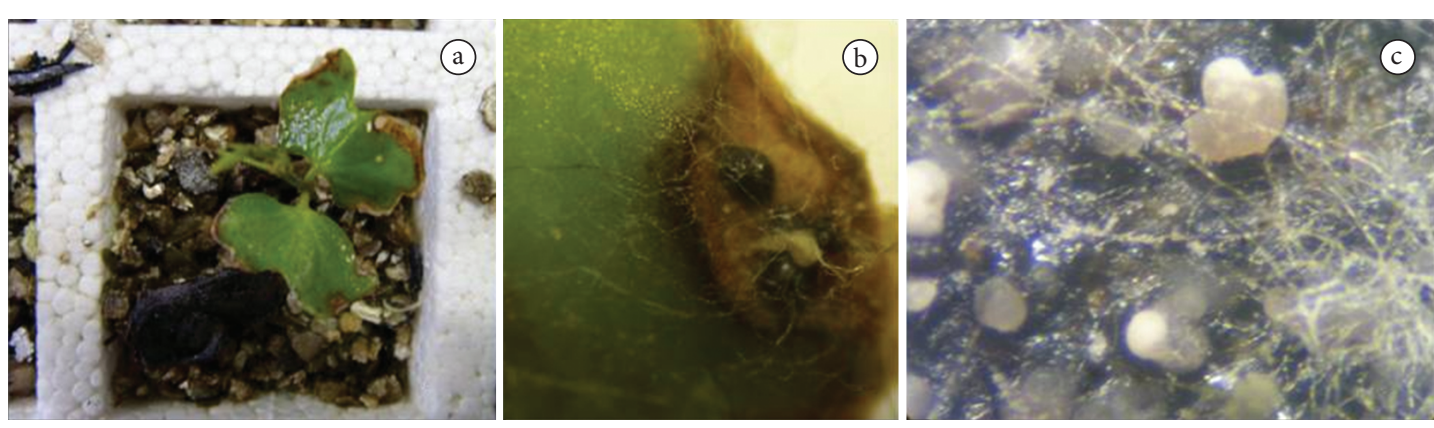

Figura 1. Material vegetativo de Parapiptadenia rigida infectado com Phomopsis sp. no teste de patogenicidade. a) Plântula com sintoma de necrose nos bordos dos folíolos; b) Detalhe dos bordos dos folíolos com a presença de picnídios do patógeno visto no microscópio estereoscópico; c) Picnídios do patógeno na semente vistos no microscópio estereoscópico.

Figure 1. Vegetative material Parapiptadenia rigida infected with Phomopsis sp. in the pathogenicity test. a) seedling symptom of necrosis on the leaflet's edges; b) detail of the leaflet's edges with the presence of the pathogen seen on a stereoscopic microscope; c) pycnidia of the pathogen in seed seen on a stereoscopic microscope.

na germinação para essa procedência. Resultados semelhantes foram relatados por Santos et al. (1998), nos quais Phomopsis sp. também teve influência no vigor e na germinabilidade de sementes de caroba [Cybistax antisyphilitica (Mart.) Mart.], impedindo a germinação ou necrosando a radícula e o embrião. Santos et al. (1997) encontraram o patógeno associado a sementes de baru (Dipteryx alata Vog.), espécie comum no Cerrado, causando a redução de germinação e a formação de sintomas de pósemergência em plântulas.

De acordo com os resultados de sementes não germinadas (SNG) (Tabela 3), verificou-se que houve interação entre os fatores procedências e tratamento (sementes inoculadas e não inoculadas). A procedência e o tratamento das sementes apresentaram efeito significativo sobre o número de SNG. Para a procedência SCS, observou-se que $37 \%$ das sementes inoculadas com Phomopsis sp. não germinaram, diferindo do resultado observado para as sementes não inoculadas (14\%). As sementes não germinadas apresentaram sintomas de enrugamento e encontravam-se recobertas por frutificações negras (Figura 1c). Em um trabalho semelhante com sementes de soja, que permaneceram em contato com o inóculo por 48 horas, Machado et al. (2001) verificaram que Phomopsis sojae é extremamente agressivo, ocasionando uma redução de 20\% na germinação. De acordo com Goulart (1997), Phomopsis sojae causa a seca da haste e da vagem quando associada a sementes de soja, reduzindo a qualidade do grão.

No teste de patogenicidade (Figura 1a e b), foi verificado que o fungo Phomopsis sp. provocou lesões necróticas escuras nos bordos dos folíolos e, sobre a lesão, constatou-se a presença de frutificações negras (picnídios), pelas quais era exsudada uma massa gelatinosa, constituída pelos conídios alfa e beta do fungo. Os mesmos sintomas foram observados por Anjos et al. (2001), em mudas de aroeira (Myracrodruon urundeuva Fr.All.) inoculadas com Phomopsis sp. Assim, após o reisolamento, confirmou-se a transmissão por sementes e a patogenicidade do isolado Phomopsis sp. em plântulas de angico-vermelho da procedência Santa Cruz do Sul-RS.

\section{STATUS DA SUBMISSÃO}

Recebido: 15/10/2012

Aceito: 26/03/2013

Publicado: 30/06/2013

\section{AUTOR(ES) PARA CORRESPONDÊNCIA}

\section{Clair Walker}

Departamento de Defesa Fitossanitária, Universidade Federal de Santa Maria - UFSM, CEP 97105-900, Santa Maria, RS, Brasil e-mail: clairwalker@gmail.com 


\section{REFERÊNCIAS}

Anjos JRN, Charchar MJA, Guimarães DP. Ocorrência de queima das folhas causada por Phomopsis sp. em aroeira no Distrito Federal. Fitopatologia Brasileira 2001; 26(3): 649-650. http://dx.doi. org/10.1590/S0100-41582001000300012

Barnett HL, Hunter BB. Illustred genera of imperfect fungi. 3rd ed. Minneapolis: Burgess Publishing Company; 1972. $241 \mathrm{p}$.

BotelhoLS, MoraesMH,MentenJOM.Fungosassociados às sementes de ipê-amarelo (Tabebuia serratifolia) e ipê-roxo (Tabebuia impetiginosa): incidência, efeito na germinação e transmissão para as plântulas. Summa phytopathologica 2008; 34(4): 343-348. http://dx.doi. org/10.1590/S0100-54052008000400008

Brasil. Ministério da Agricultura, Pecuária e Abastecimento. Regra para análise de sementes. Brasília, 2009. 399 p.

Carneiro JS. Testes de sanidade de sementes de essências florestais. In: Soave J, Wetzel MVS. Patologia de sementes. Campinas: Fundação Cargill; 1987. 480 p.

Carvalho PER. Espécies arbóreas brasileiras. Colombo: Embrapa Florestas; 2003. 1039 p.

Cherobini EAI, Muniz MFB, Blume E. Avaliação da qualidade da semente e mudas de cedro. Ciência Floresta 2008; 18(1): 65-73.

Ferreira DF. Estatística básica. 2. ed. Ampliada e revisada. Lavras: UFLA; 2009. 664 p.

Goulart ACP. Fungos em sementes de soja: detecção e importância. Dourados: Embrapa/CPAO; 1997. 58 p.

Lazarotto M, Muniz MFB, Santos AF. Detecção, transmissão, patogenicidade e controle químico de fungos em sementes de paineira (Ceiba speciosa). Summa Phytopathologica 2010; 36 (2): 134-139. http:// dx.doi.org/10.1590/S0100-54052010000200005

Lorenzi H. Árvores Brasileiras: manual de identificação e cultivo de plantas arbóreas do Brasil. 5. ed. Nova Odessa: Instituto Plantarum; 2008. 384 p.

Machado JC. Patologia de sementes: fundamentos e aplicações. Brasília: Ministério da Educação, Lavras: ESAL/FAEPE; 1988. 107 p.

Machado JC, Oliveira JA, Vieira MGGC, Alves MC. Inoculação artificial de sementes de soja por fungos, utilizando solução de manitol. Revista Brasileira de Sementes 2001; 23(2): 95-101.

Maciel CG, Muniz MFB, Santos AF, Lazarotto M. Detecção, transmissão e patogenicidade de fungos em sementes de Parapiptadenia rigida (angico-vermelho). Summa Phytopathologica 2012; 38(4):323-328. http:// dx.doi.org/10.1590/S0100-54052012000400009

Mendes SS, Santos PR, Santana GC, Ribeiro GT, Mequita JB. Levantamento, patogenicidade e transmissão de fungos associados às sementes de sabiá (Mimosa caesalpiniaefolia Benth). Revista Ciência Agronômica 2005; 36(1): 118-122.

Mondo VHV, Brancalion PH, Cicero SM, Novembre ADLC,DouradoNetoD. Testedegerminaçãodesementes de Parapiptadenia rigida (Benth.) Brenan (Fabaceae). Revista Brasileira de Sementes 2008; 30(2): 177-183. http://dx.doi.org/10.1590/S0101-31222008000200022

Nakagawa J. Testes de vigor baseados no desempenho das plântulas. In: Krzyzanowski FC, Vieira RD, França Neto JB, editor. Vigor de sementes: conceitos e testes. Londrina: ABRATES. 1999. 218 p.

Padulla TL, Moraes MHDM, Barbedo CJ, Borges IF, Menten JOM, Pascholati SF. Detecção de fungos em sementes de pau-brasil (Caesalpinia echinata) coletadas durante sua formação e dispersão. Revista Brasileira de Sementes 2010; 32(2):154-159. http://dx.doi. org/10.1590/S0101-31222010000200019

Resende MLV, Pádua MA, Toyota M. Manejo de doenças associadas a viveiros florestais. In: Davide AC, Silva EAA. Produção de sementes e mudas de espécies florestais. Lavras: UFLA, 2008. v. 1, p. 80-89.

Santos MF, Ribeiro WRC, Faiad MGR, Sano SM. Fungos associados às sementes de baru (Dipteryx alata Vog.). Revista Brasileira de Sementes 1997; 19(1): 135-139.

Santos MF, Ribeiro WRC, Faiad MGR, Salomão AN. Avaliação da qualidade sanitária e fisiológica das sementes de caroba (Cybistax antisyphilitica (Mart.) Mart.). Revista Brasileira de Sementes 1998; 20(1): 1-6.

Santos AF, Medeiros ACS, Santana DL. Fungos associados a espécies arbóreas da Mata Atlântica. Colombo: Embrapa-CNPF. Boletim de Pesquisa Florestal 2001; 42:57-70.

Strapasson M, Santos AF, Medeiros ACS. Fungos associadosàs sementes de angico (Piptadeniapaniculata). Boletim de Pesquisa Florestal 2002; 45:137-141. 